\title{
Parental Explanatory Style and Its Relationship to the Classroom Performance of Disabled and Nondisabled Children ${ }^{1}$
}

\author{
Anne Vanden Belt and Christopher Peterson, ${ }^{2}$ \\ University of Michigan
}

This study examined the relationship between the explanatory style of parents for events involving their school-aged children and the children's classroom performance. Parents and teachers of 52 disabled and 40 nondisabled elementary school students completed questionnaires. Those children whose parents attributed bad events to internal, stable, and global causes tended not to fulfill their potential in the classroom, according to ratings by their teachers. The same patterns held for both disabled and nondisabled children. Findings suggest that the attributional beliefs of parents can affect the behavior of their children.

KEY WORDS: explanatory style; academic performance; parental influence; disability.

This study explores one possible explanation for the discrepancy between the apparent potential and the actual performance of children in the classroom. Perhaps this discrepancy is produced at least in part by parental attitudes, specifically, the characteristic ways in which parents explain events involving their children. Explanatory style is a cognitive personality variable that has been linked to depression (Peterson \& Seligman, 1984), illness (Peterson \& Seligman, 1987), and poor achievement in

${ }^{1}$ This paper is based on an honors thesis in psychology at the University of Michigan, completed by the first author under the supervision of the second author. We wish to thank Jane Somers for making this research possible. Lisa M. Bossio gave helpful editorial advice. Anne Vanden Belt is now at the School of Medicine, University of Pennsylvania.

${ }^{2}$ Address all correspondence to Christopher Peterson, Department of Psychology, University of Michigan, 580 Union Drive, Ann Arbor, Michigan 48109. 
diverse settings, including school (Peterson \& Barrett, 1987). However, its role within a family has yet to be explicitly examined. We hypothesize that the explanatory style of parents affects the classroom performance of their children. Parental beliefs about the causes of events are transmitted to and internalized by children, who then act according to these beliefs, living up (or down) to them.

Explanatory style emerged from the reformulation of learned helplessness theory (Abramson, Seligman, \& Teasdale, 1978). Originally, theorists tried to explain depression as a consequence of experience with uncontrollability (Seligman, 1974, 1975). This hypothesis, however, could not explain individual differences in the severity or duration of depression following uncontrollable events, nor could it explain individual differences in the loss of self-esteem that may accompany depression.

Studies suggested that uncontrollability only resulted in helplessness and depression when the individual explained the uncontrollable events in a particular way. Accordingly, the reformulation of helplessness theory proposed that the nature of one's explanation for an uncontrollable bad event determines the generality and chronicity of a depressive reaction, as well as any loss of self-esteem. The reformulated theory predicts that those who attribute bad events to internal ("it's me"), stable ("it's going to last forever"), and global ("it's going to undercut everything I do") causes, with what we term a pessimistic explanatory style, are more likely to become depressed when bad events occur than those who exhibit an optimistic style (Peterson \& Seligman, 1984).

Research converges to support the basic premise of the helplessness reformulation that internal, stable, and global causal attributions are associated with increased depressive symptoms (Sweeney, Anderson, \& Bailey, 1986). However, explanatory style probably has a broader applicability. The reformulated helplessness theory hypothesized that explanatory style should relate to a variety of behaviors that involve inappropriate passivity and low morale. Researchers of late seem to be recognizing the potential breadth of explanatory style, because studies have been appearing that ascertain its correlates and consequences in a variety of domains.

One area where explanatory style has been investigated is classroom achievement. School performance is a likely candidate to show an influence of explanatory style. Performance obviously varies between students, and just as obviously, it is not solely a product of the student's inherent competence. Investigations with both grade school students (Nolen-Hoeusema, Girgus, \& Seligman, 1986) and college students (Peterson \& Barrett, 1987) indeed have shown that pessimistic students do not do as well as optimistic students, even when "objective" indices of ability are held constant. 
Unanswered in studies to date are questions about the origin of pessimistic versus optimistic explanatory styles. Because these causal beliefs do not strictly reflect past performances, their origin must be sought outside the student, perhaps in messages communicated to them by parents or teachers (cf. Dweck \& Leggett, 1988; Seligman et al., 1984). For instance, Graham (1984) found that student achievement is related to two possible reactions of teachers to student performance. She suggests that when teachers feel sympathetic toward children who do not perform well, the children sense that they are being treated this way because they cannot do any better and thus do not try to improve. If, on the other hand, teachers communicate a sense of anger at a poor performance, children will sense that the teacher is angry at them because they did not do as well as possible on the task. Children will then be motivated to perform better in the future since they have received the message that they are expected to do so.

Along these same lines, Parsons, Adler, and Kaczala (1982) suggested that differences in classroom achievement reflect differences in socialization. They found that parental beliefs affected children's self-perceptions. Children's self-perceptions affected their performance. Parsons et al. also found that differences in parental beliefs about children's abilities existed even when children's abilities were identical. Thus, it is the parents' interpretation of reality, not reality itself, which shapes the message they pass on to their children. Perhaps children may achieve less than they are capable of achieving because their parents somehow communicate to them that they have lesser abilities than they actually do have.

These ideas together suggest the usefulness of looking at the explanatory style of parents in relation to the academic performance of their children. Pessimistic parents should have children who fail to work up to their potential; optimistic parents should have children who do particularly well in school. To maximize the relevance of parental explanatory style to children's academic performance, we examined the explanatory style of a group of parents for a subset of events-negative events involving their children-rather than for the broader range of events usually considered in explanatory style research. For instance, here is one of the hypothetical events we presented to parents: "Your child's teacher tells you that your child is not behaving well in class." We then asked them to explain why this event would happen. The parents of both disabled and nondisabled children filled out questionnaires which assessed explanatory style for events involving their children.

We included disabled children in our sample because their parents might tend to interpret bad events in terms of their child's disabilities. Discussions of disability frequently mention the importance of beliefs and 
attitudes in determining the reaction of the disabled child to his or her challenge (e.g., Canino, 1981; Grimes, 1981; Wilgosh, 1984), but no research has taken a look at causal beliefs held by the parents and how these end up influencing the performance of the child. We hypothesized that the parents of disabled children might be more likely to display ? pessimistic explanatory style than the parents of nondisabled children.

To measure classroom performance, we asked each child's teacher to fill out a questionnaire that rated each child's performance in light of his or her ability. Although this measure may be influenced in unknown ways by teacher bias, we chose to rely on it because the most valid assessment of a child's performance must take into account each child's particular mesh of skills. Thus, teacher ratings seem a more useful measure for our purposes than would be "absolute" measures like grades.

\section{METHOD}

\section{Subjects and Procedure}

The participants in this study were parents and teachers of elementary school students who attend a public school in Michigan. The school is a magnet school for all disabled students in the district; it also serves as a neighborhood school for regular education students. Permission slips and questionnaires were sent home with 150 special education students and 150 students in "regular" classrooms. One parent of each child was asked to sign a consent form, complete the questionnaire, and then return the materials to the child's teacher in a sealed envelope. Those parents who gave permission for their child's teacher to complete a questionnaire were asked to sign the outside of the envelope. There was a label near the seal of the outside of the envelope which reminded parents to affix their signatures there as well as on the parental consent form. This ensured confidentiality by obviating the need for the teacher to open the envelope to see whether or not the consent form was signed.

The teachers of those students whose parents gave permission for them to fill out questionnaires did so. In all, questionnaires were completed by both parents and teachers of 52 special education and 40 regular education students. Fifteen different teachers provided ratings for the 92 children. There were 52 male and 40 female students, with approximately the same male:female ratio in both types of classes. Of the 92 parents, 79 chose to identify their child's race; there were one Asian, fourteen black, 
Table I. Events on Questionnaire Asseessing Parental Explanatory Style

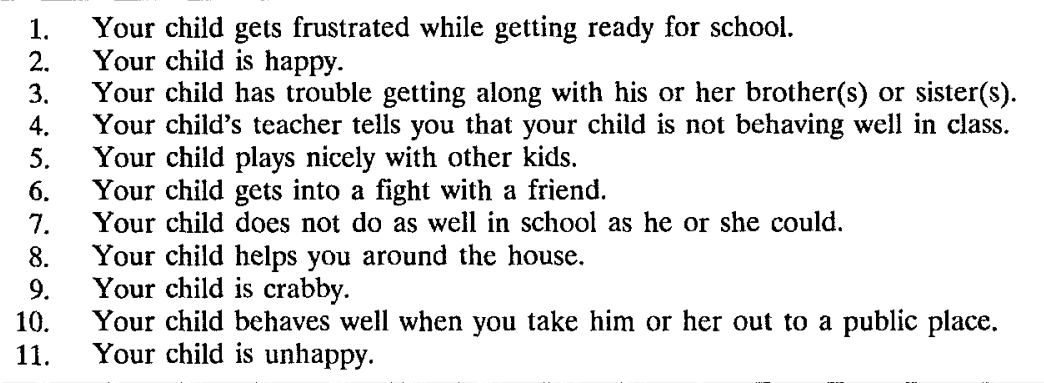

fifty-six white, one Hispanic, and seven Native American students in our sample.

Our subjects were in kindergarten through sixth grade. The disabilities represented in our sample included hearing impairment, vision impairment, health impairment, mental retardation, and learning disability. According to the teachers, of the 92 children in the sample, 35 had a disability visible to a causal observer; 44 had a disability that entailed a physical challenge; and 13 had a disability that entailed an intellectual challenge.

\section{Questionnaires}

Parent Measures. Each parent was given a packet of three questionnaires. The first questionnaire requested basic demographic information concerning the child. The second questionnaire assessed explanatory style, and was adapted from a similar measure devised by Alexander (1988) for assessing the explanatory style of family members who were the caretakers of head-injured individuals. This questionnaire asked the parent to imagine each of a series of events involving their child. Seven of these were bad events, and four were good events (see Table I).

With respect to each event, the parent used 5-point rating scales asking about the number of situations in which the child acts this way (globality) and the likelihood of the child acting this way in the future (stability). Parents were also asked if there was anything they could do to change a bad event or maintain a good event (internality). Ratings on each scale were averaged across events, separately for bad events and for good events (cf. Peterson et al., 1982; Peterson \& Villanova, 1988). Composite explanatory style scores were then formed by averaging the internality, stability, and globality scores, again separately for bad events and good 
Table II. Reliabilities of Parent Measures $(N=92)$

\begin{tabular}{lll}
\hline & Mean $(S D)$ & Alpha \\
\hline Explanatory style for bad events & & \\
$\quad$ Internality & $3.28(0.87)$ & .80 \\
Stability & $2.32(0.69)$ & .74 \\
Globality & $2.14(0.74)$ & .75 \\
Composite & $2.56(0.56)$ & .83 \\
Explanatory style for good events & & \\
$\quad$ Internality & $3.80(0.86)$ & .72 \\
Stability & $4.28(0.56)$ & .38 \\
Globality & $4.09(0.65)$ & .51 \\
Composite & $4.06(0.52)$ & .72 \\
\hline
\end{tabular}

events. Table II shows the reliabilities of these measures, estimated by Cronbach's (1951) coefficient alpha. Most of these figures were highly satisfactory, including all those for bad events.

The third questionnaire completed by the parents was brief, asking about their habitual moods. Answers here were unrelated to measures of their children's classroom performance. Accordingly, we will not again mention this questionnaire.

Teacher Measures. Teachers completed a questionnaire that assessed each student's adjustment and achievement in the classroom in relation to that child's potential. Taking into account the child's disability, teachers used 5 -point scales (from $1=$ poor to $5=$ excellent) to rate the child's:

1. Academic achievement

2. Behavior in the classroom

3. Ability to meet reasonable challenges

4. Social skills

5. Ability to cope with failure

6. Overall performance in relation to his or her potential

7. Emotional adjustment to being disabled

8. Physical adjustment to being disabled

9. Happiness

The ratings about adjustment to disability were not made by teachers of the nondisabled children. Teacher ratings tended to correlate, so a composite adjustment/achievement score was created by averaging across the relevant items. The reliability of this measure for the disabled students was .94 , and the reliability for nondisabled students was .93 . 
Table MI. Correlations between Explanatory Style and Classroom Performance ${ }^{a}$

\begin{tabular}{|c|c|c|c|c|c|c|c|}
\hline \multirow[b]{2}{*}{ Teacher rating } & \multirow[b]{2}{*}{ Mean $(S D)$} & \multicolumn{3}{|c|}{$\begin{array}{l}\text { Composite style for } \\
\text { bad events }\end{array}$} & \multicolumn{3}{|c|}{$\begin{array}{l}\text { Composite style for } \\
\text { good events }\end{array}$} \\
\hline & & DIS & NON & TOT & DIS & NON & TOT \\
\hline Academic achievement & $3.00(0.99)$ & $-.27^{b}$ & $-.42^{c}$ & $-.32^{c}$ & .00 & $.32^{b}$ & $.17^{d}$ \\
\hline Behavior in classroom & $3.13(1.17)$ & $-.28^{b}$ & $-.32^{b}$ & $-.28^{c}$ & .09 & .15 & .13 \\
\hline Ability to meet challenges & $2.75(1.13)$ & -.21 & $-.43^{c}$ & $-.30^{c}$ & .07 & $.33^{b}$ & $.18^{d}$ \\
\hline Social skills & $3.00(1.12)$ & -.15 & $-.34^{b}$ & $-.20^{d}$ & -.08 & .20 & .05 \\
\hline Ability to cope with failure & $2.54(0.91)$ & -.15 & $-.32^{b}$ & $-.20^{d}$ & -.04 & $.32^{b}$ & .12 \\
\hline $\begin{array}{l}\text { Overall performance in relation to } \\
\text { potential }\end{array}$ & $2.97(1.16)$ & $-.27^{b}$ & $-.39^{\circ}$ & $-.32^{c}$ & .04 & .24 & .12 \\
\hline Emotional adjustment & $3.19(1.05)$ & -.20 & - & - & .04 & - & - \\
\hline Physical adjustment & $3.33(0.92)$ & .08 & - & - & .05 & - & 一 \\
\hline Happiness & $3.52(1.06)$ & $-.26^{d}$ & $-.27^{d}$ & $-.28^{c}$ & .01 & .13 & .03 \\
\hline Composite & $3.02(0.88)$ & $-.25^{d}$ & $-.42^{c}$ & $-.32^{c}$ & .02 & $.27^{d}$ & .14 \\
\hline
\end{tabular}

${ }^{a}$ Note: Abbreviations are as follows: DIS $=$ disabled students $(n=52)$, NON $=$ nondisabled students $(n=40)$, and TOT $=$ total sample $(n=92)$.

${ }^{b} p<.10$.

$\varepsilon_{p}<.05$.

$a_{p}<.01$.

\section{RESULTS}

Here is an overview of the findings. Parental explanatory style was related as predicted to the classroom performance of children. Pessimistic parents had students who did not work up to their potential. The same patterns held for both disabled and nondisabled children.

Explanatory Style and Classroom Performance. Table III presents the correlations between parental explanatory style and teacher ratings of children's classroom behaviour and achievement. These correlations indicate that a pessimistic explanatory style is associated with poor classroom adjustment and achievement, for both disabled and nondisabled students.

Table III also shows the analogous correlations between parental explanatory style for good events and teacher ratings. Here, explanatory style was associated with classroom adjustment and performance only for nondisabled students. These results are less striking than those for bad events, perhaps because the explanatory style measure for good events was less reliable and/or perhaps because explanations for good events seem rarely to be as psychologically revealing as those for bad events (Peterson \& Seligman, 1984).

Not shown in Table III are the correlations involving the individual dimensions of explanatory style. Briefly, the significant links between overall explanatory style and classroom performance reflect mainly correlations 
with the dimensions of stability and globality. Internality did not play much of a role at all.

Comparisons. Age of student was unrelated to any of the parent or teacher measures. The hypothesized difference between parents of disabled and those of nondisabled children with respect to explanatory style was not found. Nor were there differences in the mean teacher ratings for these two groups of students.

Sex and race differences in mean scores were also ascertained. Male vs. female comparisons revealed no differences. The only racial groups large enough to allow comparisons were blacks $(n=14)$ and whites $(n=$ 56). The only significant difference with respect to race was that the parents of black students explained bad events more pessimistically than the parents of white students ( 3.06 vs. $2.42, t=4.47, p<.001)$.

\section{DISCUSSION}

The central hypothesis of the present study was that the explanatory style of parents would be related to the classroom performance of their children. As predicted, pessimistic explanatory style on the part of parents was negatively correlated with how teachers assessed the social and academic adjustment of children. We presume that parental beliefs were transmitted to children, who internalized them, and then acted in accordance with them, in ways that classroom teachers could detect. Additionally or alternatively, the explanatory style of parents may have reflected the kinds of opportunities and challenges they provided for their children.

Our data are cross-sectional, however, which means that these suggested processes may not reflect the actual direction of effects. It is conceivable that the child's performance affected the parent's explanatory style, rather than vice versa. Or perhaps teacher expectations were the beginning of the chain, influencing how the children performed (cf. Rosenthal \& Jacobson, 1968), which in turn shaped the explanations offered by parents.

A definitive resolution of this issue is impossible with the present data. We nonetheless argue that the sequence of effects we advocate is plausible. First, explanatory style is a highly stable individual difference and thus resistant to change (Burns \& Seligman, 1989). Second, the various alternatives to our premise that cognitions determine performance propose instead that "reality" in the form of actual student performance and/or teacher judgments drive the effects. If this were the case, there should have 
been some discernible influence of a child's disability on the parent's causal explanations. There was no such influence.

Although we have just used the lack of difference between disabled and nondisabled children to support the validity of our cross-sectional design and the conclusions it suggests, we did expect a difference. Our initial notion was that at least some parents of disabled children would attribute bad events to their child's disability, resulting in an average difference between the explanatory styles of parents of disabled vs. nondisabled students. That no overall difference was found is therefore surprising. For whatever reasons, parents and teachers alike seemed to render all students "ordinary" treatment, thus precluding a difference which might be found in another population. Perhaps there was a self-selection bias into the study, because participation was optional.

Explanatory style for good events was related to the teacher ratings in a direction opposite to that found for explanatory style for bad events; however, the correlations were weaker. This finding converges with previous findings reported by Peterson and Seligman (1984) and many others. Perhaps explanations of good events are less consistent and less powerful predictors because people put less emphasis on explaining events that go well (Wong \& Weiner, 1981).

For both good and bad events, the stability and globality of parental attributions proved to be better predictors of teacher ratings than did internality. This is probably related to the fact that "internality" here reflects the amount of responsibility the parent felt for the child's actions. Perhaps internal attributions are only significant when they are internal to the person actually involved in the event. Thus, it is not having "internal" or "external" parents that influences children, but rather the perceived message that they themselves do or do not cause bad events.

The difference between parents of black and white students is worth noting. The parents of black children were more pessimistic than the parents of the white children, even though their children were doing about the same in the classroom. There have been several discussions of the relevance of learned helplessness ideas to minority populations in the United States (e.g., Bowman, 1984; Seligman, 1975; Sue, 1977), but these are the only data of which we are aware that actually finds race differences in explanatory style. Further investigations are warranted, particularly of how these differences on the part of parents might eventually start to influence their children.

The present study has several limitations that lead us to temper our conclusions. We have already noted that the design was cross-sectional, not longitudinal. Also, the return rate of permission slips and questionnaires was disappointingly low $(92 / 300=31 \%)$, resulting in a sample of unknown 
representativeness. Finally, our measures were all developed for this study, so the present data represent their only validity evidence.

At the same time, our results are intriguing enough to imply that future research should be undertaken. That the findings held for both disabled and nondisabled students supports their generality. In future investigations, longitudinal designs should be employed to tease out the possible directions of effects. We have assumed that the major influence runs from parent to child, but bidirectional effects are of course possible. A multiwave longitudinal study might uncover what actually is happening.

The magnitude of our obtained correlations may seem modest at first glance (but see Rosenthal, 1990, for a discussion of the size of correlation coefficients). However, in light of all the possible influences on classroom performance, the fact that parental explanatory style bears any kind of a statistically significant relationship is striking. Perhaps the most important implication of the present study is that the problem of underachieving students can be tackled from yet another angle: intervening with parents with regard to how they explain events involving their children. Techniques exist that can reliably change explanatory style from pessimistic to optimistic (Seligman et al., 1988), and there is no reason why these cannot be adapted for parents of school children. Academic adjustment and achievement of children might be bolstered simply by encouraging their parents to believe that improvement is possible (cf. Wilson \& Linville, 1982, 1985).

\section{REFERENCES}

Abramson, L. Y., Seligman, M. E. P., \& Teasdale, J. D. (1978). Learned helplessness in humans: Critique and reformulation. Journal of Abnormal Psychology, 87, 49-74.

Alexander, M. (1988). The effects on caretakers of caring for a head injured relative. Unpublished doctoral dissertation, University of Michigan, Ann Arbor.

Bowman, P. J. (1984). A discouragement-centered approach to studying employment among Black youth: Hopelessness, attributions, and psychological distress. International Journal of Mental Health, 13, 68-91.

Burns, M. O., \& Seligman, M. E. P. (1989). Explanatory style across the life span: Evidence for stability over 52 years. Joumal of Personality and Social Psychology, 56, 471-477.

Canino, F. J. (1981). Learned helplessness theory: Implications for research in learning disabilities. Journal of Special Education, 15, 471-484.

Cronbach, L. J. (1951). Coefficient alpha and the internal structure of tests. Psychometrika, 16, 297-334.

Dweck, C. S., \& Leggett, E. L. (1988). A social-cognitive approach to motivation and personality. Psychological Review, 95, 256-273.

Graham, S. (1984). Teacher feelings and student thoughts: An attributional approach to affect in the classroom. The Elementary School Journal, 85, 91-104.

Grimes, L. (1981). Learned helplessness and attribution theory: Redefining children's learning problems. Learning Disability Quarterly, 4, 91-100. 
Nolen-Hoeksema, S., Girgus, J. S., \& Seligman, M. E. P. (1986). Learned helplessness in children: A longitudinal study of depression, achievement, and explanatory style. Journal of Personality and Social Psychology, 51, 435-442.

Parsons, J., Adler, T., \& Kaczala, C. (1982). Socialization of achievement attitudes and beliefs: Parental influences. Child Development, 53, 310-321.

Peterson, C., \& Barrett, L. C. (1987). Explanatory style and academic performance among university freshmen. Journal of Personality and Social Psychology, 53, 603-607.

Peterson, C., \& Seligman, M. E. P. (1984). Causal explanations as a risk factor for depression: Theory and evidence. Psychological Review, 91, 347-374.

Peterson, C., \& Seligman, M. E. P. (1987). Explanatory style and illness. Journal of Personality, $55,237-265$.

Peterson, C., et al. (1982). The Attributional Style Questionnaire. Cognitive Therapy and Research, 6, 287-299.

Peterson, C., \& Villanova, P. (1988). An Expanded Attributional Style Questionnaire. Joumal of Abnormal Psychology, 97, 87-89.

Rosenthal, R. (1990). How are we doing in soft psychology? American Psychologist, 45, 775-777.

Rosenthal, R., \& Jacobson, L. (1968). Pygmalion in the classroom. New York: Holt, Rinehart, \& Winston.

Seligman, M. E. P. (1974). Depression and learned helplessness. In R. J. Friedman \& M. M. Katz (Eds.), The psychology of depression: Contemporary theory and research (pp. 83-113). Washington, DC: Winston.

Seligman, M. E. P. (1975). Helplessness: On depression, development, and death. San Francisco: Freeman.

Seligman, M. E. P., et al. (1988). Explanatory style change during cognitive therapy for unipolar depression. Journal of Abnormal Psychology, 97, 13-18.

Seligman, M. E. P., et al. (1984). Attributional style and depressive symptoms among children. Journal of Abnormal Psychology, 93, 235-238.

Sue, S. (1977). Psychological theory and implications for Asian Americans. Personnel and Guidance Joumal, 55, 381-389.

Sweeney, P. D., Anderson, K., \& Bailey, S. (1986). Attributional style in depression: A meta-analytic review. Journal of Personality and Social Psychology, 50, 974-991.

Wilgosh, L. (1984). Learned helplessness in normally achieving and learning disabled girls. Mental Retardation and Learning Disability Bulletin, 12, 64-70.

Wilson, T. D., \& Linville, P. W. (1982). Improving the academic performance of college freshmen: Attribution therapy revisited. Joumal of Personality and Social Psychology, 42, 367-376.

Wilson, T. D., \& Linville, P. W. (1985). Improving the academic performance of college freshmen with attributional techniques. Joumal of Personality and Social Psychology, 45, 287-293.

Wong, P. T. P., \& Weiner, B. (1981). When people ask "why" questions, and the heuristics of attribution search. Journal of Personality and Social Psychology, 40, 649-663. 